\title{
The Pilot Influence on the Flutter Velocity of the Lightweight Plane
}

\author{
Tomáš Sommer ${ }^{1}$, Pavel Steinbauer ${ }^{2}$, Svatomir Slavík ${ }^{1}$, Miloslav Vilímek ${ }^{2}$, Aleš Kratochvíl ${ }^{1}$ \\ ${ }^{1}$ Dept. of A erospace Engineering, Faculty of M echanical Engineering, Center of A dvanced A erospace Technology, \\ Czech Technical University in Prague, Technická 4, 16607 Praha 6, Czech Republic \\ ${ }^{2}$ Dept. of M echanics, Biomechanics and M echatronics Engineering, Faculty of M echanical Engineering, Czech \\ Technical University in Prague, Technická 4, 16607 Praha 6, Czech Republic
}

\begin{abstract}
Flutter of the airplane is serious problem which is carefully investigated during design and testing both computationally and experimentally. The lightweight plane dynamics is however influenced by pilot, by his muscular transfer function. This study shortly describes results of experimental investigation of pilot's modal characteristics from $1 \mathrm{~Hz}$ up to $70 \mathrm{~Hz}$. Next discusses the pilot influence on modal parameters of longitudinal flight control system of lightweight airplane. The change is aimed on the natural frequency and damping. This study also discusses the change of flutter velocity with dependence of new modal parameters influenced by pilot. Including a comparison with the current methodology free and blocked longitudinal flight control system.
\end{abstract}

\section{Introduction}

This paper is focused on experimental determination of pilot influence on the modal parameters of the longitudinal mechanical control system. This change of modal parameters causes a change in the dynamic stability of the structure - the flutter velocity. Many publications dealt with the pilot's response to various stimuli. The focus was mainly on the pilot's response to low-frequency stimuli and traffic delays in relation to flight dynamics [13].

Main aim of this work is description of influence of pilot arm on dynamical characteristics mechanical control line and description of the influence on the flutter velocity. Determining, where pilot's properties are among the boundary conditions of free and blocked control at flutter computation. This work is limited in defining the influence of one pilot on the velocity of the flutter.

The publication [1] deals with the description of a pilot system stimulated optically by a change in flight altitude, studying the transport delay of response to stimulus in the area of longitudinal, transverse and directional control. It sets transfer functions for all three control directions. Comparison of models with experimental data was performed up to $8 \mathrm{~Hz}$. In [2], the measurement of pilot response to altimeter data change is described, the range of test 
frequencies being from 0.029 to $3.5 \mathrm{~Hz}$. A state description was used to identify the pilot, with the pass-through matrix of the input entering the output equal to zero. The accuracy of four different models is tracked. The publication [3] deals with the description of the pilot's behaviour in the system of two degrees of freedom related to longitudinal and lateral control. The experiment was performed on each axis separately, the maximum excitation frequency was about $16 \mathrm{~Hz}$.

None of these studies is however aimed at interaction of the pilot and airplane in the full frequency range from $1 \mathrm{up}$ to $70 \mathrm{~Hz}$, where flutter is studied.

\section{Pilot description}

The measured pilot properties from [4] was used. The measured properties were subsequently described by the state space model shown in Fig. 1. It was used general state space system complied by function $n 4$ sid in MATLAB. A "free" calculation method was chosen, meaning that the state matrix of internal bonds $\mathrm{A}$, the binding matrix at input $\mathrm{B}$ and the output matrix at state $\mathrm{C}$ were estimated. The solution of the input-to-output binding matrix D was entered. Furthermore, a non-solving of the noise component of the K-matrix was set, which had zero values set

$$
\begin{aligned}
& d x(t)=A x(t)+B u(t) \\
& y(t)=C x(t)+D u(t)
\end{aligned}
$$

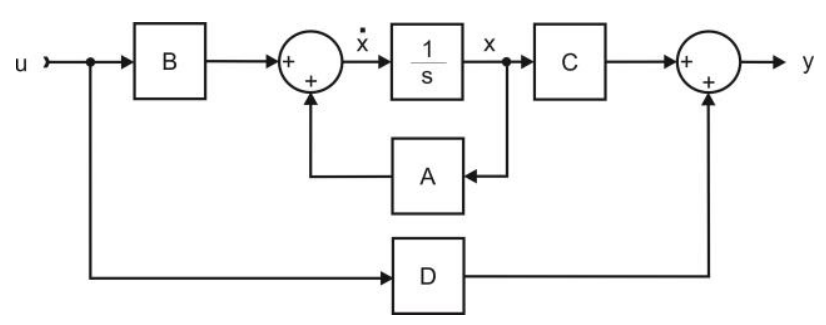

Fig. 1. Diagram of state space model

This state space model of pilot description had to be inverted. Inversion was based on publication [5], which allows an inversion of SISO state space systems. This inverted state space system was connected with state space system of free longitudinal flight control system using negative feedback function in MATLAB. 


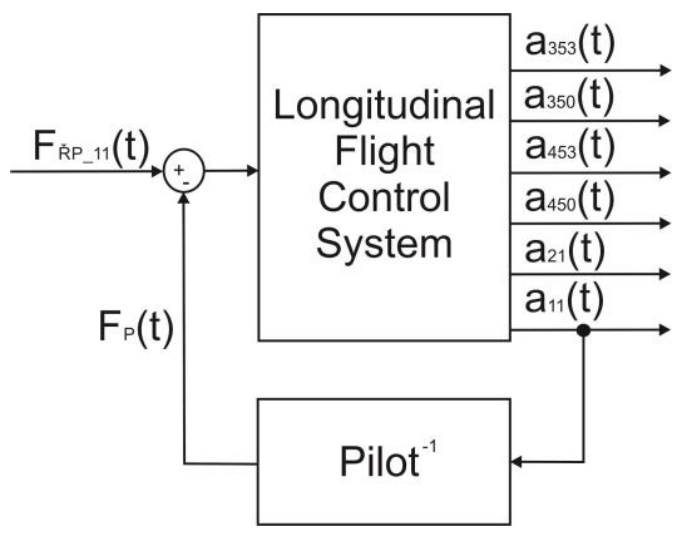

Fig. 2. Diagram of system interconnection

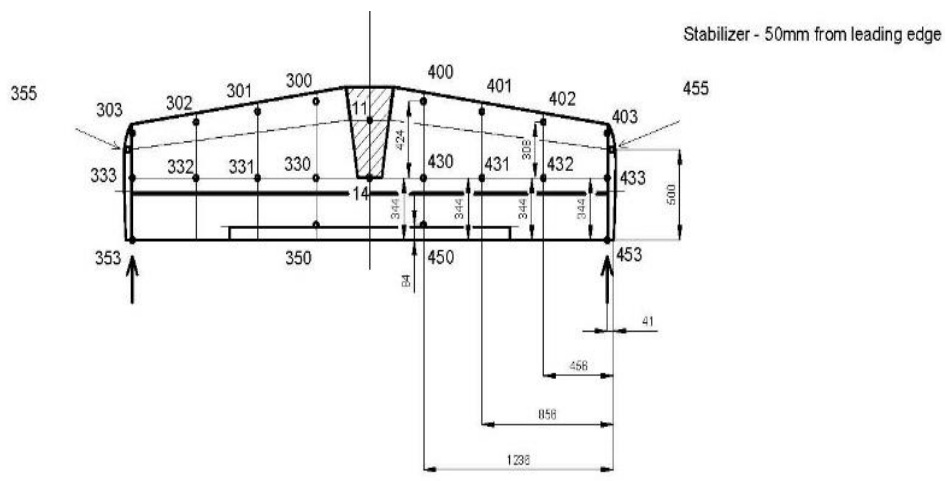

Fig. 3. A ccelerometer sensor placement

Fig. 2. presents SIMO system described using state space model of longitudinal flight control system with the interconnection of inverted state space model of the pilot. State space system of longitudinal flight control system describes real structure of two seats light sport aircraft. $\mathrm{F}_{\mathrm{R}_{-}}{ }_{1} 11$ is excitation force placed on left control stick. The axx indicates acceleration at tail plane shows on Fig. 3, a11 and a 21 are accelerometers placed on left side and right side control stick. At point 11 the pilot and the flight control system were interacting. The modal parameters of free flight control system is presented in Table 1. The modal parameters of blocked flight control system is presented in Table 2.

Table 1. Modal parameters of free flight control system

\begin{tabular}{|c|c|}
\hline \multicolumn{2}{|c|}{ Free flight control system } \\
\hline Eigen frequency [Hz] & Damping [\%] \\
\hline 3,225 & 21,056 \\
\hline 24,439 & 3,074 \\
\hline
\end{tabular}

Table 2. Modal parameters of blocked flight control system

\begin{tabular}{|c|c|}
\hline \multicolumn{2}{|c|}{ Blocked flight control system } \\
\hline Eigen frequency [Hz] & Damping [\%] \\
\hline 9,226 & 6,323 \\
\hline 25,336 & 1,745 \\
\hline
\end{tabular}


Change of modal parameters after free flight control system and inverted pilot system connection are listed in below. For purpose of this article was chosen typical pilot in six configurations. The configurations were: three levels of excitation signal amplitude: $1 \mathrm{~V}$, $2 \mathrm{~V}, 3 \mathrm{~V}$ and the type of pilot grip. Two types of pilot grip were studied. The first one simulated the normal grip of the control stick by the pilot, which is common in the standard traffic situations like horizontal flight etc. The second one was intended to simulate a fixed grip of the control stick in which pilot tries to suppress the movement of control stick resulting from dynamic phenomena. This is a boundary condition, which can be compared and which approaches to a blocked control stick. The modal parameters of interconnection systems are presented in Table 3 and Table 4.

Table 3. Change of modal parameters of interconnection systems for normal grip

\begin{tabular}{|l|r|r|r|}
\hline \multicolumn{1}{|c|}{$\begin{array}{c}\text { Change of modal } \\
\text { parameters }\end{array}$} & \multicolumn{3}{|c|}{ Normal grip } \\
\cline { 2 - 4 } & \multicolumn{1}{|c|}{$\mathbf{~ V}$} & \multicolumn{1}{|c|}{$\mathbf{~ V}$} & \multicolumn{1}{|c|}{$\mathbf{3 ~ V ~}$} \\
\hline Frequency [Hz] & 3,283 & 3,113 & 3,108 \\
\hline $\boldsymbol{\Delta}$ Frequency [\%] & 1,798 & $-3,473$ & $-3,628$ \\
\hline Damping [\%] & 33,518 & 33,203 & 32,964 \\
\hline $\boldsymbol{\Delta}$ Damping [\%] & 59,185 & 57,689 & 56,554 \\
\hline Frequency [Hz] & 24,637 & 24,457 & 24,418 \\
\hline $\boldsymbol{\Delta}$ Frequency [\%] & 0,810 & 0,074 & $-0,086$ \\
\hline Damping [\%] & 4,679 & 4,499 & 4,339 \\
\hline $\boldsymbol{\Delta}$ Damping [\%] & 52,212 & 46,357 & 41,152 \\
\hline Frequency [Hz] & - & 27,603 & - \\
\hline $\boldsymbol{\Delta}$ Frequency [\%] & - & 12,947 & - \\
\hline Damping [\%] & - & 99,692 & - \\
\hline$\Delta$ Damping [\%] & - & 3143,071 & - \\
\hline
\end{tabular}

Table 4. Change of modal parameters of interconnection systems for fixed grip

\begin{tabular}{|c|c|c|c|}
\hline \multirow{2}{*}{$\begin{array}{c}\text { Change of modal } \\
\text { parameters }\end{array}$} & \multicolumn{3}{|c|}{ Fixed grip } \\
\hline & $1 \mathrm{~V}$ & $2 \mathrm{~V}$ & $3 \mathrm{~V}$ \\
\hline Frequency $[\mathrm{Hz}]$ & 2,954 & 3,848 & 3,488 \\
\hline$\Delta$ Frequency [\%] & $-8,403$ & 19,318 & 8,155 \\
\hline Damping [\%] & 25,232 & 52,225 & 38,503 \\
\hline$\Delta$ Damping [\%] & 19,833 & 148,029 & 82,860 \\
\hline Frequency [Hz] & 23,516 & 25,525 & 24,896 \\
\hline$\Delta$ Frequency $[\%]$ & $-3,777$ & 4,444 & 1,870 \\
\hline Damping [\%] & 62,790 & 11,809 & 13,871 \\
\hline$\Delta$ Damping $[\%]$ & 1942,615 & 284,157 & 351,236 \\
\hline Frequency [Hz] & 25,561 & - & 26,743 \\
\hline$\Delta$ Frequency $[\%]$ & 4,591 & & 9,428 \\
\hline Damping [\%] & 15,449 & - & 69,790 \\
\hline$\Delta$ Damping [\%] & 402,570 & - & 2170,332 \\
\hline
\end{tabular}

\section{Flutter analysis}

The calculation of flutter resistance was performed using the internal program "Flutter 2D-2.0". The program was created at the Institute of Aerospace Engineering, CTU in Prague and uses MATLAB programming environment. The program works with a mathematical model of the "P-K" type [6]. It is the most widely used method of calculation of flutter resistance in practice. This is an iterative method that is a compromise between the "P" and "K" methods. The method assumes harmonic oscillation for the aerodynamic 
part of the model and any movement for the structural part of the model. The "P-K" method is calculated in the frequency domain. Aerodynamic load id based on Theodorsen model of oscillating profile.

The procedure for calculating the flutter resistance of the structure was identical to the calculation performed for the purpose of aircraft certification of ultralight airplanes. The calculation was made only for the tail. Calculation methodology separates wing and tail calculations separately and does not assume interaction of wing influence on tail surfaces and vice versa. The pilot's properties were included in the calculation for $0 \mathrm{~km} / \mathrm{h}$ and were not back-iterated during the calculation for each velocity point. The program is based on the entered parameters for the entire calculation. For the calculation, the influence of the flight control system was adjusted, which was supplemented with arm parameters. The effect of air compressibility was neglected during the calculation. The calculation was made in addition to the pilot's influence for both free and blocked longitudinal flight control system.

\subsection{Influence of flight control system}

The influence of the flight control system was simulated by the so-called additional moment of inertia $\Delta \mathrm{J}$, which was added to the moment of inertia of the control surface as follows:

$$
J=J_{\text {o.o. }}+\Delta J
$$

The additional moment of inertia was determined according to the application of the so-called Kiessling methodology and simulates the inertial effects of moving rods and levers associated with control surface movement. The scheme of the flight control system for computation of additional moment of inertia is presented in Fig. 4. The flight control system is also assigned the mass of the pilot's wrist and forearm [7-9]. The calculated values of the additional inertia moments for the control surface are given in [10,11]. Pilot's action weight of upper limb was determined to $2,120 \mathrm{~kg}$ and translation of gravity center was determined to $0,238 \mathrm{~m}$.

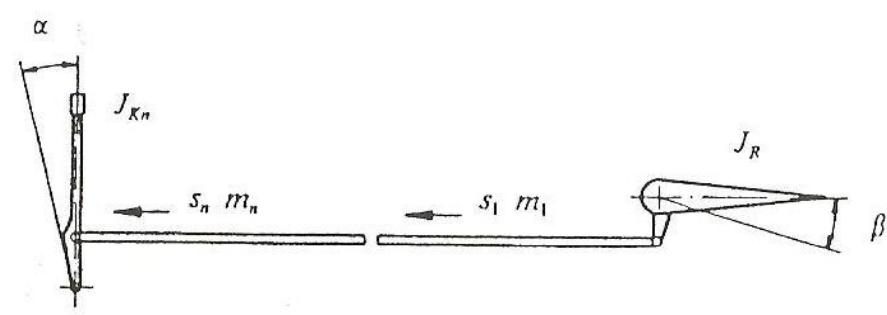

Fig. 4. Scheme of flight control system [5]

Formula used to calculate additional moment of inertia:

$$
\Delta J=\sum_{\text {rodi } i}\left(\frac{d s}{d \beta}\right)_{i}^{2} m_{i}+\sum_{\text {levey } i}\left(\frac{d \omega}{d \beta}\right)_{i}^{2} J_{i}
$$

Where: $\Delta \mathrm{J}$ - additional moment of inertia [kg.m2], ds - translation motion of the rod $[\mathrm{m}], \mathrm{m}_{\mathrm{i}}$ - weight of the rod $[\mathrm{kg}], \mathrm{d} \alpha$ - deflection angle of the lever [rad], $\mathrm{J}_{\mathrm{i}}-$ moment of 
inertia of the lever to the axis of rotation [kg.m2], $\mathrm{d} \beta$ - control surface angle of rotation [rad].

For symmetrical shapes the value of coefficient Kiessling function 1 was chosen, for antisymmetrical shapes the coefficient value of 0,2 was chosen. Such a low value was chosen due to the assumption of additional moments of inertia in the vicinity of the nodal point (line) of the elevator. Used additional moments of inetria are presented in Table 5.

Additional moments of inertia:

Table 5. Additional moments of inertia of flight control system

\begin{tabular}{|c|c|r|r|}
\hline \multicolumn{2}{|c|}{$\Delta \mathbf{J}\left[\mathbf{k g} \cdot \mathbf{m}^{2}\right]$} & \multicolumn{2}{c|}{ Control surface } \\
\cline { 3 - 4 } & & Elevator - Left & Elevator - Right \\
\hline \multirow{2}{*}{$\begin{array}{c}\text { Free flight control } \\
\text { system }\end{array}$} & Symmetrical shapes & 0,0387 & 0,0387 \\
\cline { 2 - 4 } & Antisymmetrical shapes & 0,0000 & 0,0000 \\
\hline $\begin{array}{c}\text { Fixed flight control } \\
\text { system }\end{array}$ & Symmetrical shapes & 0,0290 & 0,0290 \\
\cline { 2 - 4 } $\begin{array}{c}\text { Flight control system } \\
\text { with pilot }\end{array}$ & Antisymmetrical shapes & 0,0000 & 0,0000 \\
\cline { 2 - 4 } & Symmetrical shapes & 0,1996 & 0,1996 \\
\hline
\end{tabular}

\subsection{Flutter velocity}

The velocity of the flutter was determined for tail-plane of light and heavy configuration, free and blocked longitudinal flight control system (FCS) and pilot described above. The altitude of $0 \mathrm{~m}$ above sea level was solved according to ISA. Calculated flutter velocities are presented in Table 6. and in Fig. 5.

Table 6. Flutter velocities with influence of the pilot 1

\begin{tabular}{|c|c|c|c|c|c|c|c|c|c|c|}
\hline \multirow{3}{*}{\multicolumn{3}{|c|}{ Case }} & \multicolumn{4}{|c|}{ Light configuration } & \multicolumn{4}{|c|}{ Heavy configuration } \\
\hline & & & \multicolumn{2}{|c|}{ SY } & \multicolumn{2}{|c|}{ ANTI } & \multicolumn{2}{|c|}{ SY } & \multicolumn{2}{|c|}{ ANTI } \\
\hline & & & $\begin{array}{c}V_{F L} \\
{[\mathbf{k m} / \mathbf{h}]}\end{array}$ & $\begin{array}{c}\Delta V_{\text {FL }} \\
{[\%]}\end{array}$ & $\begin{array}{c}V_{F L} \\
{[\mathbf{k m} / \mathbf{h}]}\end{array}$ & $\begin{array}{c}\Delta V_{F L} \\
{[\%]}\end{array}$ & $\begin{array}{c}V_{\mathrm{FL}} \\
{[\mathrm{km} / \mathrm{h}]}\end{array}$ & $\begin{array}{c}\Delta V_{F L} \\
{[\%]}\end{array}$ & $\begin{array}{c}V_{F L} \\
{[\mathrm{~km} / \mathbf{h}]}\end{array}$ & $\begin{array}{c}\Delta V_{F L} \\
{[\%]}\end{array}$ \\
\hline \multicolumn{3}{|c|}{ Free FCS } & 364,1 & 0 & 615 & 0 & 338,9 & 0 & 591,4 & $\mathbf{0}$ \\
\hline \multicolumn{3}{|c|}{ Blocked FCS } & - & - & 397,3 & $-35,4$ & - & - & 402,3 & $-32,0$ \\
\hline \multirow{6}{*}{$\begin{array}{l}\nabla_{1}^{\prime} \\
\stackrel{\vec{\theta}}{\vec{\theta}} \\
\end{array}$} & \multirow{3}{*}{$\begin{array}{l}\text { Normal } \\
\text { grip (1) }\end{array}$} & $1 \mathrm{~V}$ & 434,4 & 20,3 & 615,0 & 0,0 & 409,9 & 21,0 & 591,6 & 0,0 \\
\hline & & $2 \mathrm{~V}$ & 425,7 & 17,9 & 615,0 & 0,0 & 399,3 & 17,8 & 592,9 & 0,3 \\
\hline & & $3 \mathrm{~V}$ & 424,7 & 17,6 & 615,0 & 0,0 & 398,3 & 17,5 & 592,6 & 0,2 \\
\hline & \multirow{3}{*}{$\begin{array}{c}\text { Fixed } \\
\text { grip (2) }\end{array}$} & $1 \mathrm{~V}$ & 402,7 & 11,6 & 615,0 & 0,0 & 374,3 & 10,4 & 591,8 & 0,1 \\
\hline & & $2 \mathrm{~V}$ & 541,7 & 50,1 & 615,0 & 0,0 & 595,5 & 75,7 & 589,3 & $-0,4$ \\
\hline & & $3 \mathbf{V}$ & 458,6 & 27,0 & 615,0 & 0,0 & 438,9 & 29,5 & 591,2 & 0,0 \\
\hline
\end{tabular}




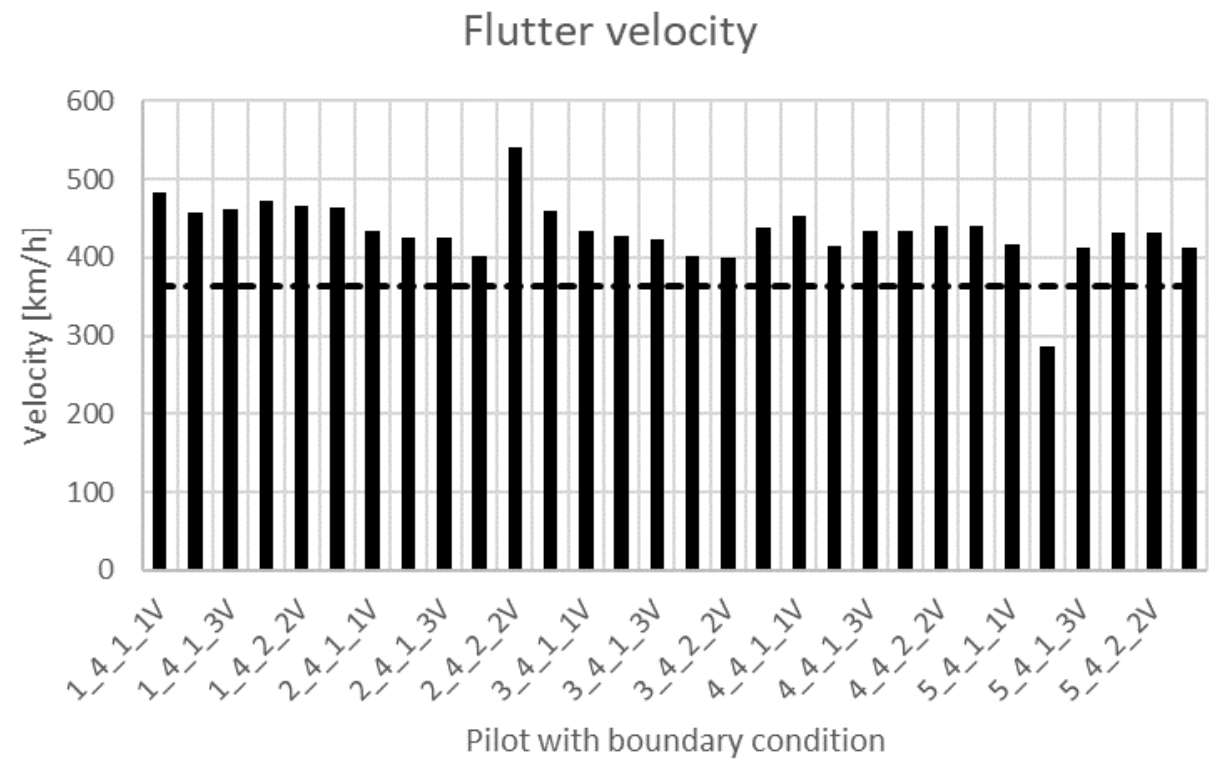

Fig. 5. Influence of pilots on flutter velocity with different boundary conditions for light configuration

\section{Conclusion}

Based on the idea of describing the pilot's influence on the dynamic stability of the structure during flight, an experiment was organized. The experiment was carried out on 5 five pilots under laboratory conditions, with one typical pilot mentioned in this article. The results indicate a positive effect of the pilot on the flutter velocity in terms of tail surfaces. The change in velocity is evident mainly for the symmetrical shape of the vibration, in this case the shape of vibration is a rigid body motion. Table 6 presents the variations in flutter velocity between $10 \%$ and $75 \%$ relative to the critical flutter velocity of the airplane with free control. From the data needed to calculate the flutter stability, the velocity result is most influenced by the mass of the pilot's hand, which was applied to the calculation of the additional moment of inertia. Determination of masses and center of gravity was based on publications [7-9]. The influence of the change of natural frequencies is evident for the calculation mainly in case, according to the measured data, that one natural frequency is divided into two frequencies. This occurred in one unpublished specimen and the flutter critical velocity dropped sharply by $25 \%$. Changes in pilot grip or excitation amplitudes for affecting non-linearity are not evident despite the expectation. The critical flutter velocity with pilot have a large standard deviation.

\section{Discussion}

This study complements the boundary conditions under which the flutter resistance of ultralight aircraft is calculated. The critical flutter velocity with pilot results support the idea that the pilot's properties are between free and blocked control. These results are consistent with the fact that a satisfactory flutter airplane construction tested for free and blocked control is stable even when connected to a pilot. A pilot who has reduced the flutter critical velocity will be further researched. 


\section{Acknowledgments}

Author acknowledges support from the ESIF, EU Operational Programme Research, Development and Education, and from the Center of Advanced Aerospace Technology (CZ.02.1.01/0.0/0.0/16_019/0000826), Faculty of Mechanical Engineering, Czech Technical University in Prague.

\section{References}

[1] D. T. McRuer, et al, Mathematical Models of Human Pilot Behaviour, Advisory Group for Aerospace Research and Development, Paris, France, 658.3.04:629.73.072, Jan, (1974)

[2] R. A. Hess, J. K. Moore, Estimating Parameters of the Structural Pilot Model Using Simulation Tracking Data, AIAA, Boston, 99259, (2013)

[3] G. A. Bekeley, H. F. Meissinger, R. E. Rose, Mathematical Models of Human Operators in Simple Two-Axis Manual Control Systems, IEEE Transactions on Human Factors in Electronics, p 42-52, ISSN 0096-249X, (1965)

[4] T. Sommer, P. Steinbauer, M. Vilímek, S. Slavík, A. Kratochvíl, Influence of the pilot on the modal parameters of the control system lightweight aircraft, 34th conference with international participation Computational Mechanics, p 109-110, ISBN 978-80261-0819-1,(2018)

[5] J. J. Buchholz, W. v. Grünhagen, Inversion Impossible?, GRIN Publishing; 1 edition ASIN: B076X1ZCM8, (2008)

[6] S. Slavík, K. Weigel, Flutter Calculation Model with Isolated Modal Characteristics of Control Surfaces for Small Sport Airplanes, Czech Aerospace proceeding, 2008(2), p 44-49, ISSN 1211-877X, (2008)

[7] R. F. Chandler, C. E. Clauser, J. T. McConville, H. M. Reynolds, J. W. Young, Investigation of Inertial Properties of the Human Body, Washington, DC, USA: US Department of Transportation National Highway Traffic Safety Administration, (1975)

[8] V. M. Zatsiorsky, V. N. Seluyanov, The mass and inertia characteristics of the main segments of the human body, Proceedings of the 8th International Congress of Biomechanics, pp 1152-1159, Volume 8 B, ISSN 01468197, (1983)

[9] V. M. Zatsiorsky, V. N. Seluyanov, Estimation of the mass and inertia characteristics of the human body by means of the best predictive regression equations, D. Winter, R. Norman, R. Wells, K. Hayes, A. Patla (Eds.), Biomechanics 9 B, Champaign, IL: Human Kinetics, pp 233-239, (1985)

[10] A. Kratochvíl, T. Sommer, S. Slavík, Analýza flutterové odolnosti letounu BRISTELL NG5U, ČVUT v Praze, VZP/ULT/53/2013, (2013)

[11] A. Kratochvíl, S. Slavík, Flutter Analysis of the Bristell B23 Airplane, ČVUT v Praze, VZP/ULT/7/2019, (2019) 